\title{
Plasma levels of Clusterin are representative of the early phase of the neurodegenerative process in Parkinson's disease
}

\author{
Lorenzo Polimeno $^{*}$, Artor Niccoli Asabella² ${ }^{2}$ Antonio Mazzocca ${ }^{1}$, Giovanni De Fazio $^{3}$, Riccardo Polimeno ${ }^{1}$, Rosalba Buquicchio ${ }^{4}$, Valentina \\ Lavelli $^{2}$ and Giuseppe Rubini ${ }^{2}$ \\ ${ }^{1}$ Department of Interdisciplinary Medicine, Section of Sciences and Technologies of Laboratory Medicine, University of Bari “A. Moro”, Bari - Italy \\ ${ }^{2}$ Department of Interdisciplinary Medicine, Section of Nuclear Medicine, University of Bari “A. Moro", Bari - Italy \\ ${ }^{3}$ Department of Basic Sciences, Neuroscience and Sense Organs, Section of Neurology, University of Bari "A. Moro”, Bari -Italy \\ ${ }^{4}$ Department of Biomedical Science and Human Oncology, Section of Dermatological, University of Bari “A. Moro”, Bari -Italy
}

\begin{abstract}
Background/Aim: There is no reliable diagnostic test for Parkinson's disease (PD) despite many attempts to identify specific biomarkers for early diagnose of disease. Different patterns of protein expression in cerebrospinal fluid, including the apolipoproteinJ/Clusterin (CLU), have been reported in patients with PD. CLU is implicated in many biological processes, including aging, oxidative stress and apoptosis. A colocalization of CLU with $\alpha$-synuclein, a presynaptic neuronal protein, in the cortical bodies of Lewy has been shown in patients with PD. Aim of this study was to test the hypothesis of CLU as a circulating biomarker in a cohort of patients with PD.

Materials/Methods: Ninety-six patients with PD and eighty-four age and sex matched healthy subjects (HS) were enrolled. Plasma levels of CLU were determined and a correlation with motor and neuropathological parameters of $\mathrm{PD}$ patients was performed.

Results/Conclusions: A significant increase in blood levels of CLU in PD patients, compared to HS, in subjects younger than 60 years of age (PD: $283 \pm 149 \mu \mathrm{g} /$ $\mathrm{ml}$, HS: $106 \pm 74 \mu \mathrm{g} / \mathrm{ml} ; \mathrm{p}=2.7 \times 10^{-4}$ ) was detected. No statistically significant difference was observed in subjects older than 60 years of age. Furthermore, a significant inverse correlation between CLU blood levels and the Mini Mental State Examination (MMSE) was evidenced. The increased levels of CLU in younger PD patients may have relevance as an early biomarker for PD. Determination of circulating levels of CLU may therefore facilitate an early diagnosis in patients with PD where clinical aspects are not emerged yet, thus allowing a timely therapeutic approach.
\end{abstract}

\section{Introduction}

Parkinson's disease (PD) is an age-related neurodegenerative movement disorder afflicting approximately the $2 \%$ of the population over 50 years of age [1]. Several non-motor symptoms also characterize PD patients. Diagnosis of PD is only possible through clinical signs and symptoms and by neuropathological findings at postmortem examination. By using a dopamine transporter single photon emission computed tomography (DaT-SPECT), we recently reported a widespread reduced striatal uptake in PD patients $[2,3]$. Nevertheless, there is no specific laboratory test available for $\mathrm{PD}$, therefore, selective biomarkers to assist in the diagnosis of $\mathrm{PD}$ are needed.

The molecular pathogenesis of PD involves multiple molecular and cellular mechanisms such as $\alpha$-synuclein proteostasis, mitochondrial function, oxidative stress and cellular apoptosis [4], many of which are implicated in aging in other neurodegenerative diseases such as Alzheimer's disease (AD) and the Multiple system atrophy (MSA) [5-7]. In this contest, previous studies have reported significant biochemical changes in the cerebrospinal fluid (CSF) of patients with PD, including changes of amyloid precursor protein, cathepsin $\mathrm{B}$ precursor [8], chromogranin B and apoliprotein H [9] and CLU [10]. In particular, CLU has been found to colocalize with $\alpha$-synuclein filaments in Lewy bodies in PD patients [11]. All these observations lead to the hypothesis of a putative role of Clusterin in the pathogenesis of PD.
CLU is a secreted heterodimeric glycoprotein with a ubiquitous expression in human tissues. CLU is implicated in many processes, including oxidative stress, apoptosis, cell cycle regulation and DNA repair. CLU is one of the most studied circulating molecular chaperones, a functional class of proteins whose predominant function is the prevention of unsuitable associations and the aggregation of non-folded polypeptide chains, particularly under cellular/oxidative stress conditions. Such conditions can occur in neurodegenerative diseases and determine cellular apoptosis. CLU has been localized in both the cytoplasm (secretory CLU- sCLU) and in the nucleus (nCLU). In these different locations, the two isoforms act in an opposite way in determining cell survival or cell death. In fact, the sCLU isoform is thought to be an anti-apoptotic factor [12-18], whereas the nCLU isoform is shown to retain pro-apoptotic activity [19-21].

In this study, we hypothesize that plasma levels of CLU could represent an early marker for $\mathrm{PD}$, whose determination may facilitate

Correspondence to: Lorenzo Polimeno, Dept of Interdisciplinary Medicine, Section of Sciences and Technologies of Laboratory Medicine, School of Medicine, University of Bari “A. Moro", Piazza G. Cesare, 11, 70124 Bari- Italy

Received: March 09, 2018; Accepted: March 16, 2018; Published: March 20, 2018 
the diagnosis of PD in younger patients, when the clinical signs of disease are not well evident yet, thus allowing a timely diagnosis and prompt therapeutic interventions.

\section{Material and methods}

\section{Patients}

Ninety-six patients with PD were recruited from the outpatients attending the Clinic for Neurological Disorders and Neuroscience Sense Organ of the University of Bari. Patients with parkinsonism different from Parkinson's disease, dementia and severe comorbidities, such as infectious, inflammatory, neoplastic and metabolic diseases were excluded from the study. The research has been performed in accordance with the Helsinki Declaration and all patient signed an informed consent of General Authorization for the Processing of Personal Data for scientific research Purposes, according the National legislative decree (Italian Official Gazette n. 72, 26th March 2012). The present is a retrospective study carried out on blood samples collected over the years and stored in the Clinic for Neurological Disorders and Neuroscience Sense Organ, Department of Neurology at the University of Bari School of Medicine. This collection was carried out in times when, for human studies, no ethical approval was required, and the informed consent signed by the patients was sufficient for research studies. PD was diagnosed using the British Brain Bank Criteria [22]. Information on age, sex, duration of parkinsonian motor symptoms and on the levodopa equivalent dose (LED) for dopamine agonists and levodopa were collected. A motion disorders specialist evaluated basic parkinsonian signs (tremor, rest, stiffness and bradycin) and motor complications (including motor fluctuations and dyskinesia). The Unified Parkinson's Disease Rating Scale Part III and Part IV 8UPDRS-III and UPDRS-IV) and the staging of Hones and Yahr (HY) were measured after one night of elimination from the drug circus with a period of a wash out of at least 12 hours. The neuropsychological examination was also evaluated by a psychologist, including the Mini Mental State Examination (MMSE) [23]. The FAS verbal fluidity test [24], the Geriatric Depression Scale [25], the Activities of Daily Living (ADL) and the Instrumental Activities of Daily Living (IADL) were also determined in PD patients. Both motor and neuropsychological information were obtained on the same day of blood sampling for laboratory analyzes. Eighty-four healthy subjects (Healthy Subjects group-HS), matched for age and sex with PD patients, were recruited among relatives of outpatients with neurological diseases other than parkinsonism. Demographic, motor and neuropsychological parameters evaluation of the subjects included in the study are reported in Table 1 and Table 2.

\section{Blood-EDTA Sampling and laboratory tests}

Human Clusterin blood determination. Plasma-EDTA clusterin levels were determined using a commercial kit by BioVendor Laboratory Medicine, Inc (DBA, Segrate Milano, Italy), Venous blood samples were taken from all subjects after an overnight fast and collected using EDTA as anticoagulant. For PD's patients blood sampling has been taken after one night from the elimination of the drug, with a wash out period of at least 12 hours. Plasma samples were centrifuged at $1100 \mathrm{~g}$ for $10 \mathrm{~min}$. at $4{ }^{\circ} \mathrm{C}$ and the supernatant carefully collected. Each sample, divided in $0.5 \mathrm{ml}$ aliquots, was stored at $-70^{\circ} \mathrm{C}$ until clusterin evaluation using a sandwich ELISA method-Biotin-labeled antibody. The minimum detectable limit of clusterin was $0.50 \mu \mathrm{g} / \mathrm{l}$, repeatability in three levels in 8 replicates b6\%. Precision: Intermediate precision was $9 \%$. In the BioVendor Human Clusterin ELISA, standards, quality controls and samples are incubated in microplate wells pre-coated with
Table 1. Demographic and motor parameters of subjects involved in the study.

\begin{tabular}{|c|c|c|c|c|c|c|}
\hline & Age (yrs) & Sex & $\begin{array}{c}\text { Average } \\
\text { age of PD } \\
\text { onset (yrs) }\end{array}$ & $\begin{array}{c}\text { Length } \\
\text { average } \\
\text { of motor } \\
\text { symptoms } \\
\text { (yrs) }\end{array}$ & $\begin{array}{c}\text { HY } \\
\text { staging } \\
\text { (mean } \\
\text { score) }\end{array}$ & $\begin{array}{c}\text { UPDRS- } \\
\text { III } \\
\text { (mean } \\
\text { score) }\end{array}$ \\
\hline $\begin{array}{c}\text { PD } \\
\text { patients }\end{array}$ & $66.2 \pm 9.7$ & $\begin{array}{c}53 \mathrm{M} \\
43 \mathrm{~F}\end{array}$ & $60 \pm 9$ & $6.2 \pm 4.2$ & $1.7 \pm 0.7$ & $27.4 \pm 12.9$ \\
\hline $\begin{array}{c}\text { Normal } \\
\text { subjects }\end{array}$ & $63.8 \pm 12.1$ & $41 \mathrm{M}$ & & & & \\
\hline $\begin{array}{c}\text { Statistical } \\
\text { evaluation }\end{array}$ & $\mathrm{p}=0.3$ & & & & & \\
\hline
\end{tabular}

Table 2. Neuropsychological evaluation of PD patients.

\begin{tabular}{|c|c|c|}
\hline MMSE (mean score) & FAS (mean score) & GDS (mean score) \\
\hline $26 \pm 4$ & $22 \pm 11$ & $9 \pm 6$ \\
\hline
\end{tabular}

monoclonal anti-human clusterin antibody. After 60 min incubation and washing, biotin labeled second monoclonal anti-human clusterin antibody is added and incubated with captured clusterin for 60 minutes. After another washing, streptavidin-HRP conjugate is added. After 30-minutes incubation and the last washing step, the remaining conjugate is allowed to react with the substrate solution (TMB). The reaction is stopped by addition of acidic solution and absorbance of the resulting yellow product is measured. The absorbance is proportional to the concentration of CLU. A standard curve is constructed by plotting absorbance values against concentrations of standards, and concentrations of unknown samples are determined using this standard curve.

\section{Statistical analysis}

The data obtained are expressed as mean + standard deviation $(M$ $+\mathrm{SD})$. Statistical comparison among groups was determined using analysis of variance test (ANOVA). Where indicated, individual comparisons were performed using Student's $t$-test. The relationship between CLU blood levels and the age of PD patients has been evaluated by the Spearman test. Statistical significance was ascribed to the data when $p<0.05$.

\section{Results}

To identify CLU as an early marker of PD, we determined plasma levels of CLU in a cohort of PD patients of different age, ranging from 50 to 80 years old, and compared the data with age- and sex-matched control healthy subjects (HS). The data obtained indicate no difference in plasma levels of CLU in subjects older than 60 years of age, regardless of PD or HS.

Plasma levels of CLU in PD and HS are shown in Figure 1. No difference was observed in the two groups, even though a minor expression of CLU in HS compared to PD patients appears as a trend $(196 \pm 129 \mu \mathrm{g} / \mathrm{ml} v s 241 \pm 139 \mu \mathrm{g} / \mathrm{ml}$, HS $v s$ PD respectively). However, when we performed the analysis by grouping the subjects aged, we found that plasma levels of CLU resulted elevated in patients with PD compared to HS in the group of patients younger than 60 years of age. In fact, levels of CLU in both groups of subjects were not statistically different $(237 \pm 135 \mu \mathrm{g} / \mathrm{ml} v s 222 \pm 133 \mu \mathrm{g} / \mathrm{ml}$, respectively for HS, forty-three subjects, and for PD, fifty-one patients), when subjects were older than 60 years. In contrast, when CLU plasma levels from younger subjects $(<60$ years old age) were compared $(106 \pm 74 \mu \mathrm{g} /$ $\mathrm{ml} v s 283 \pm 149 \mu \mathrm{g} / \mathrm{ml}$, respectively for HS, forty-one subjects, and for $\mathrm{PD}$, forty-five patients), a statistically significant difference ( $\mathrm{p}=2.7 \mathrm{x}$ $10^{-4}$ ) was observed, as shown in Figure 2 . We also found a statistically significant difference $\left(\mathrm{p}=2.5 \times 10^{-3}\right)$ between the HS divided in younger 


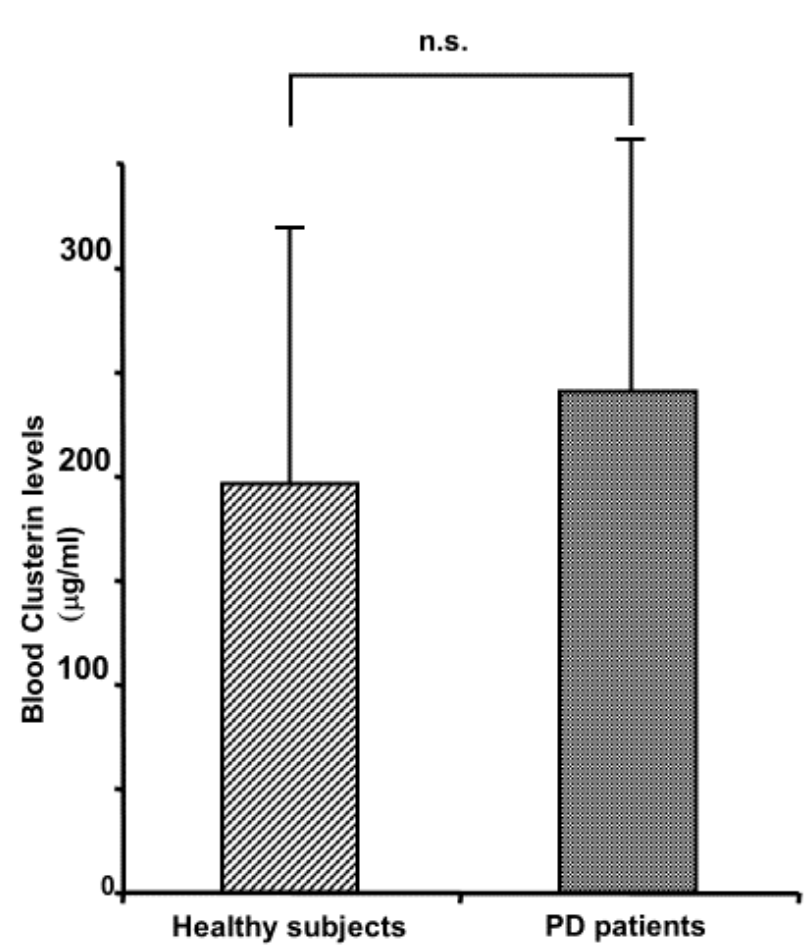

Figure 1. Circulating levels of CLU in both healthy subjects $(196 \pm 129 \mu \mathrm{g} / \mathrm{ml})$ and PD patients $(241 \pm 139 \mu \mathrm{g} / \mathrm{ml})$ are reported. No statistical difference was revealed between the two groups of subjects if compared without dividing them for decades of age.

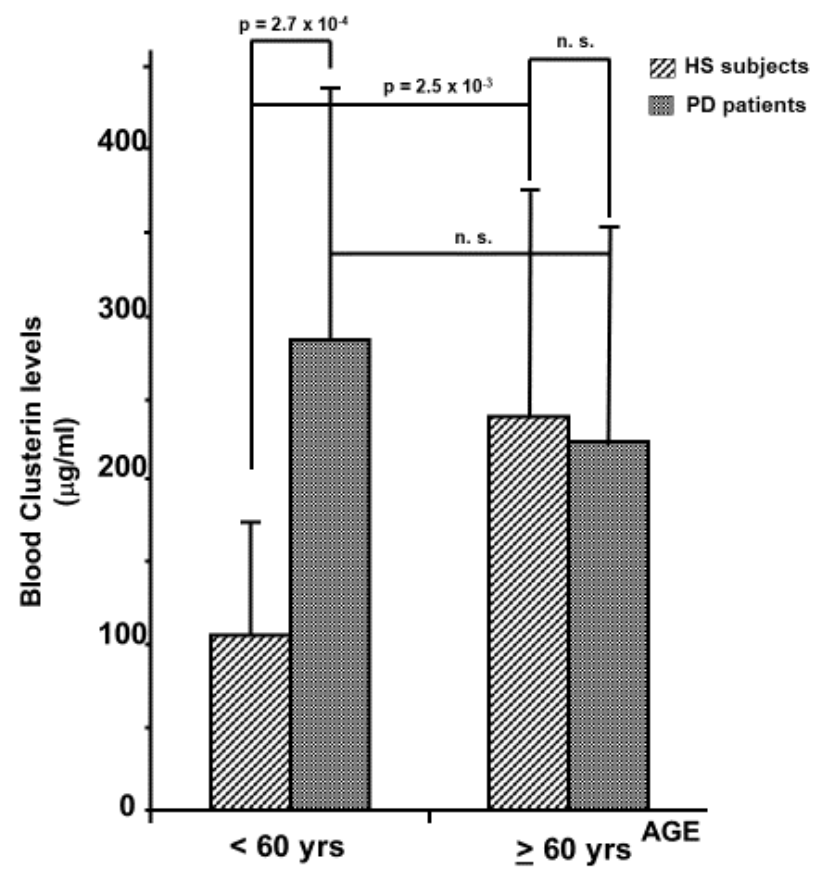

Figure 2. Circulating levels of CLU in healthy subjects and PD patients grouped by age are shown. A statistically significant difference $\left(p=2.7 \times 10^{-4}\right)$ of CLU levels between PD patients and HS was observed when data from people younger than 60 years of age were compared $(106 \pm 68 \mu \mathrm{g} / \mathrm{ml} v s 283 \pm 149 \mu \mathrm{g} / \mathrm{ml}$, respectively). No difference was evidenced comparing subjects of the two groups (HS vs PD) older than 60 years of age.

In the same Figure the statistical analysis of circulating levels of CLU in HS, divided in younger or older of 60 years of age, is also reported. Statistically $\left(\mathrm{p}=2.5 \times 10^{-3}\right)$ different levels of CLU were detected between the two groups of subjects $(106+68 \mu \mathrm{g} / \mathrm{ml}$ and $237+$ $135 \mu \mathrm{g} / \mathrm{ml}$ for younger or older subjects respectively). Instead, no difference was evidenced comparing younger $(<60$ yrs of age) versus older $(\geq 60$ yrs of age) PD patients.
( $<60$ years old age) and older ( $>60$ years old age) subjects, supporting the hypothesis, in our conditions, that aging could mask the hypersecretion of CLU related to the neurodegenerative process.

The analysis by Spearman test revealed a significant $(\mathrm{p}=1.3 \times 10$ ${ }^{3}$ ) inverse correlation between plasma levels of CLU and age of PD patients $(\mathrm{r}=-0.4)$, not present in HS group $(\mathrm{r}=-0.04)$ (Table 3). In addition, the age-appropriate linear multivariate regression analysis displayed a significant $\left(\mathrm{p}=6.0 \times 10^{-3}\right)$ inverse correlation between CLU blood levels and MMSE in PD patients $(r=-22.6)$, whereas no correlation was found between plasma levels of CLU and FAS verbal fluidity test, the duration of motor symptoms and the staging of Hones and Yahr (Table 4).

\section{Discussion}

Our findings clearly demonstrate that plasma levels of CLU are elevated in younger PD patients $(<60$ years old age) compared to HS of same age and that this can behave as an early marker of the degenerative process in PD. In addition, our study shows an inverse correlation between plasma levels of CLU and the data obtained from the evaluation of MMSE, similarly to data previously reported in Alzheimer disease. Indeed, several authors demonstrated that plasma levels of CLU inversely correlate with MMSE and that they are associated with a faster cognitive decline in patients with Alzheimer's disease [26-28]. Our data regarding HS younger than 60 years old are in line with the report by Trougakos and collaborators [29] on a similar cohort of healthy subjects.

As we report in this paper, CLU is generally found elevated in old HS ( $\geq 60$ years old age) and this could lead to misinterpreting the upregulation of CLU determined by the neurodegenerative process in PD. This study shows that plasma levels of CLU should be measured in younger PD patients, when CLU expression is still not masked by the age related increased levels. In this regard, Collier and co-workers have shown that impaired proteasome/lysosome function, oxidative stress, and inflammation, which increase with advanced age and which actively produce a vulnerable pre-parkinson state, are relevant processes that are correlated with dopamine neuron degeneration in PD [30]. Our findings support this point of view, which can determine a related precocious hyper-expression of CLU level in CSF, suggesting the easy and safe determination of CLU in the blood as an early marker of the pathogenesis of the neurodegenerative process. Indeed, increased levels of CLU in the CSF of patients with PD, as an indicator of the neurodegenerative evolution, has been already reported by other authors [10]. In particular, a two-fold increase of CLU levels in patients with less than two years with PD compared to HS has been shown. This phenomenon was not observed in patients with more than two years suffering from PD [31].

Table 3. Correlation between clusterin blood levels and age of PD patients.

\begin{tabular}{|c|c|c|}
\hline & $\begin{array}{c}\text { Spearman test } \\
\text { (blood Clu/age) }\end{array}$ & p \\
\hline PD patients & $\mathrm{r}=-0.4$ & $1.3 \times 10^{-3}$ \\
\hline Healthy subjects & $\mathrm{r}=-0.04$ & 0.8 \\
\hline
\end{tabular}

Table 4. Multivariate linear regression. Data were corrected by age.

\begin{tabular}{|c|c|c|}
\hline Variable & Regression coefficient & p \\
\hline MMSE & -22.6 & $6.0 \times 10^{-3}$ \\
\hline FAS & 4.4 & 0.1 \\
\hline $\begin{array}{c}\text { Duration of motor } \\
\text { symptoms }\end{array}$ & -1.7 & 0.8 \\
\hline HY staging & -7.5 & 0.8 \\
\hline
\end{tabular}


Oxidative stress is involved in the neuropathogenesis of PD and several molecular mediators, including CLU, may be implicated $[29,32]$. We previously reported an up-regulation of CLU in muscle biopsies from mitochondrial-related myopathies patients, showing a correlation between up-regulation of CLU and oxidative stress found in the mitochondrial-related degenerative disease [33]. Many reports have shown that CLU is widely expressed in human tissues and has many functions in health and disease [34-36]. Furthermore, CLU has been functionally implicated in a number of physiological processes (i.e. aging) and pathological processes, including age-related diseases (i.e. neurodegenerative, cardiovascular, metabolic syndromes), and a potential role as a marker of oxidative injury has been assigned to CLU $[29,37]$. Several studies have also demonstrated that CLU acts as a cytoprotective factor against the detrimental effects of oxidants [38]. Parkinson's disease (PD) afflicts approximately $2 \%$ of the population over 50 years of age [1]. No definitive biomarkers are currently available. An important observation in PD is the presence of intraneuronal Lewy bodies, composed mainly by a-synuclein filaments with which CLU co-localizes. This formation has been considered a putative marker for neuronal degeneration [39]. Unfortunately, despite all this information, so far, a biomarker for PD is not available and diagnosis is determined solely by clinical observations helped by nuclear medicine DAT SPECT. The ability to early diagnose PD is a stringent need as well as the identification of serological markers for detection of patients with PD.

\section{Conclusion}

In conclusion we demonstrated, for the first time, a significant variation of circulating levels of CLU in PD patients compared to HS. We showed that the determination of plasma levels of CLU represents an easy and safe procedure for detecting an effective biomarker useful for an early diagnosis in young PD patients, when clinical aspects of the disease not well evident yet, and for optimizing therapeutic approach.

\section{References}

1. Thomas B, Beal MF (2007) Parkinson's disease. Hum Mol Genet 2: R183-R194. [Crossref]

2. Benamer HT, Patterson J, Grosset DG, Hadley DM, Macphee GJ, et al. (2000) Correlation of Parkinson's disease severity and duration with 123I-FP-CIT SPECT striatal uptake. Mov Disord 15: 692- 698. [Crossref]

3. Gigante AF, Defazio G, Niccoli Asabella A, Superbo M, Ferrari C, et al. (2016) Smoking in Patients with Parkinson's Disease: preliminary striatal DaT-SPECT findings. Acta Neurol Scand 134: 265-270. [Crossref]

4. Poewe W, Seppi K, Tanner CM, Halliday GM, Brundin P, et al. (2017) Parkinson disease. Nat Rev Dis Primers 3: 17013. [Crossref]

5. Nesi G, Sestito S, Digiacomo M, Rapposelli S (2017) Oxidative Stress, Mitochondrial Abnormalities and Proteins Deposition: Multitarget Approaches in Alzheimer's Disease. Curr Top Med Chem 17: 3062-3079. [Crossref]

6. Desler C, Lillenes MS, Tønjum T, Rasmussen LJ (2017) The role of mitochondrial dysfunction in the progression of Alzheimer's disease. Curr Med Chem [Crossref]

7. Ubhi K, Lee PH, Adame A, Inglis C, Mante M, et al. (2009) Mitochondrial inhibitor 3-nitroproprionic acid enhances oxidative modification of alpha-synuclein in a transgenic mouse model of multiple system atrophy. 87: 2728-2739. [Crossref]

8. Zhang J, Goodlett DR, Quinn JF, Peskind E, Kaye JA, et al. (2005) Quantitative proteomics of cerebrospinal fluid from patients with Alzheimer disease. J Alzheimers Dis 7: 125-133. [Crossref]

9. Abdi F, Quinn JF, Jankovic J, McIntosh M, Leverenz JB, et al. (2006) Detection of biomarkers with a multiplex quantitative proteomic platform in cerebrospinal fluid of patients with neurodegenerative disorders. J Alzheimers Dis 9: 293-348. [Crossref]

10. Maarouf CL, Beach TG, Adler CH, Shill HA, Sabbagh MN, et al. (2012) Cerebrospinal fluid biomarkers of neuropathologically diagnosed Parkinson's disease subjects. Neurol Res 34: 669-676. [Crossref]
11. Sasaki K, Doh-ura K, Wakisaka Y, Iwaki T (2002) Clusterin/apolipoprotein J is associated with cortical Lewy bodies: immunohistochemical study in cases with alphasynucleinopathies. Acta Neuropathol 104: 225-230. [Crossref]

12. Zhang H, Kim JK, Edwards CA, Xu Z, Taichman R, et al. (2005) Clusterin inhibits apoptosis by interacting with activated Bax. Nat Cell Biol 7: 909-1015. [Crossref]

13. Moretti RM, Montagnani Marelli M, Mai S, Mai S, Cariboni A, et al. (2007) Clusterin isoforms differentially affect growth and motility of prostate cells: possible implications in prostate tumorigenesis. Cancer Res 67: 10325-10333.

14. Kim N, Choi WS (2011) Proapoptotic role of clusterin in brain. Anat Cell Biol 44 169-175. [Crossref]

15. Polimeno L, Pesetti B, Annoscia E, Giorgio F, Francavilla R, et al. (2011) Alrp, a survival factor that controls the apoptotic process of regenerating liver after partial hepatectomy in rats. Free Radic Res 45: 534-49. [Crossref]

16. Polimeno L, Pesetti B, De Santis F, Resta L, Rossi R, et al. (2012) Decreased expression of the augmenter of liver regeneration results in increased apoptosis and oxidative damage in human-derived glioma cells. Cell Death Dis 3: e289. [Crossref]

17. Djeu JY, Wei S (2009) Clusterin and chemoresistance. Adv Cancer Res 105: 77-92. [Crossref]

18. Trougakos IP, Lourda M, Antonelou MH, Kletsas D, Gorgoulis VG, et al. (2009) Intracellular clusterin inhibits mitochondrial apoptosis by suppressing p53-activating stress signals and stabilizing the cytosolic Ku70-Bax protein complex. Clin Cancer Res 15: 48-59. [Crossref]

19. Leskov KS, Klokov DY, Li J, Kinsella TJ, Boothman DA (2003) Synthesis and functional analyses of nuclear clusterin, a cell death protein. J Biol Chem 278: 11590-600. [Crossref]

20. Scaltriti M, Bettuzzi S, Sharrard RM, Caporali A, Caccamo AE, et al. (2004) Clusterin overexpression in both malignant and nonmalignant prostate epithelial cells induces cell cycle arrest and apoptosis. Br J Cancer 91: 1842-1850. [Crossref]

21. Takase O, Minto AW, Puri TS, Cunningham PN, Jacob A, et al. (2008) Inhibition of NF-kappaB-dependent Bcl-xL expression by clusterin promotes albumin-induced tubular cell apoptosis. Kidney Int 73: 567-577. [Crossref]

22. Hughes AJ, Daniel SE, Lees AJ (1993) The clinical features of Parkinson's disease in 100 histologically proven cases. Adv Neurol 60: 595-599. [Crossref]

23. Folstein MF, Folstein SE, McHugh PR (1975) "Mini-mental state". J Psychiatr Res 12: 189-198. [Crossref]

24. Tombaugh TN, Kozac J, Rees L (1999) Normative data stratified by age and education for two measures of verbal fluency: FAS and animal naming. Arch Clin Neuropsychol 14: 167-177. [Crossref]

25. Yesavage JA, Brink TL, Rose TL, Lum O, Huang V, et al. (1983) Development and validation of a geriatric depression screening scale: a preliminary report. $J$ Psychiatr Res 17: 37-49. [Crossref]

26. Jongbloed W, van Dijk KD, Mulder SD, van de Berg WD, Blankenstein MA, et al. (2015) Clusterin Levels in Plasma Predict Cognitive Decline and Progression to Alzheimer's Disease. J Alzheimers Dis 46: 1103-1110. [Crossref]

27. Thambisetty M, Simmons A, Velayudhan L, Hye A, Campbell J, et al. (2010) Association of plasma clusterin concentration with severity, pathology and progression in Alzheimer's disease. Arch Gen Psychiatry 67: 739-748. [Crossref]

28. Schrijvers EM, Koudstaal PJ, Hofman A, Breteler MM (2011) Plasma clusterin and the risk of Alzheimer's disease JAMA 305: 1322-1326. [Crossref]

29. Trougakos IP, Gonos ES (2002) Clusterin/apolipoprotein J in human aging and cancer. Int J Biochem Cell Biol 34: 1430-1448. [Crossref]

30. Collier TJ, Kanaan NM, Kordower JH (2017) Aging and Parkinson's disease: Different sides of the same coin? Mov Disord 32: 983-990. [Crossref]

31. Přikrylová Vranová H, Mareš J, Nevrlý M, Stejskal D, Zapletalová J, et al. (2010) CSF markers of neurodegeneration in Parkinon's disease. J Neural Transm 117: 1177-1181. [Crossref]

32. Jenner P (2003) Oxidative stress in Parkinson's disease. Ann Neurol 53: S26-S36. [Crossref]

33. Polimeno L, Rossi R, Mastrodonato M, Montagnani M, Piscitelli D, et al. (2013) Augmenter of liver regeneration, a protective factor against ROS-induced oxidative damage in muscle tissue of mitochondrial myopathy affected patients. Int $J$ Biochem Cell Biol 45: 2410-2419. [Crossref]

34. Bettuzzi S (2009) Chapter 1: Introduction. Adv Cancer Res 104: 1-8. 
35. Klock G, Baiersdörfer M, Koch-Brandt C (2009) Chapter 7: Cell protective functions of secretory Clusterin (sCLU). Adv Cancer Res 104: 115-138.

36. Falgarone G, Chiocchia G (2009) Chapter 8: Clusterin: A multifacet protein at the crossroad of inflammation and autoimmunity. Adv Cancer Res 104: 139-170.

37. Rosenberf ME, Silkensen J (1995) Clusterin: physiologic and pathophysiologic consideration. Int J Biochm Cell Biol 27: 633-645. [Crossref]
38. Trougakos IP (2013) The molecular chaperone apolipoprotein J/clusterin as a sensor of oxidative stress: implications in therapeutic approaches - a mini-review. Gerontology 59: 514-523. [Crossref]

39. Wakabayashi K, Tanji K, Odagiri S, Miki Y, Mori F, et al. (2013) The Lewy body in Parkinson's disease and related neurodegenerative disorders. Mol Neurobiol 47: 495508. [Crossref]

Copyright: (C2018 Polimeno L. This is an open-access article distributed under the terms of the Creative Commons Attribution License, which permits unrestricted use, distribution, and reproduction in any medium, provided the original author and source are credited. 